\title{
Are wild flowers and insect honeydews potential food resources for adults of the olive moth, Prays oleae?
}

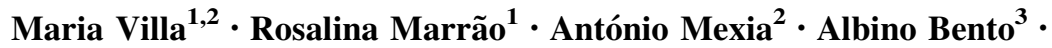 \\ José Alberto Pereira ${ }^{1}$
}

Received: 8 September 2015/Revised: 17 February 2016/ Accepted: 24 February 2016/Published online: 3 March 2016

(C) Springer-Verlag Berlin Heidelberg 2016

\begin{abstract}
The use of non-crop resources by natural enemies and their potentialities to enhance their effectiveness as pest control agents is increasing as a method for conservation biological control. Nevertheless, the effect of consumption of non-crop resources by pests has been generally overlooked being this knowledge crucial to favor natural enemies but not pests. In the present work, insect honeydews and flowers suitability as food resources for the olive tree key-pest Prays oleae were analyzed under laboratory conditions. The selected honeydews were excreted by Saissetia oleae and Euphyllura olivina, two olive pests, and the selected plants were seven abundant species in the olive grove agroecosystem that bloom simultaneously with the flight period of the anthophagous generation of $P$. oleae. In this work, some of these resources were identified as potential food sources for P. oleae. Despite the general findings, which indicate that honeydews have less nutritional value for insects than nectar, $P$. oleae reached the best survival and reproduction performance with the insects' honeydews. Several of the tested flowers were
\end{abstract}

Communicated by N. Agusti.

Electronic supplementary material The online version of this article (doi:10.1007/s10340-016-0745-8) contains supplementary material, which is available to authorized users.

José Alberto Pereira

jpereira@ipb.pt

1 School of Agriculture, Polytechnic Institute of Bragança, Campus de Santa Apolónia, 5300-253 Bragança, Portugal

2 Instituto Superior de Agronomia, Universidade de Lisboa, Tapada da ajuda, 1349-017 Lisbon, Portugal

3 Mountain Research Centre (CIMO), School of Agriculture, Polytechnic Institute of Bragança, Campus de Santa Apolónia, 5300-253 Bragança, Portugal identified as potential food resources for $P$. oleae, being Malva sylvestris the one that originated the best performance. Moreover, our results suggest that $P$. oleae females are synovigenic and emerge with nutritional reserves for reproduction. We highly recommend accomplishing further research before establishing these resources in biological control methods in order to confirm their effect on pests in fields.

Keywords Insect feeding - Non-crop resources . Praydidae $\cdot$ Saissetia oleae $\cdot$ Euphyllura olivina . Survival analysis $\cdot$ Reproduction

\section{Key message}

- Pests may feed on non-crop resources (pollen, nectar or honeydews) in some development phases; however, in the case of the olive moth, this knowledge has been overlooked.

- This is the first time that honeydews and flowers from the olive grove agroecosystem are identified as potential food sources for olive moth adults.

- These results constitute an important contribution to understand the nutritional needs of olive moth adults and will help approach more efficiently the conservation biological control of this pest.

\section{Introduction}

Habitat management is a method of conservation biological control that consists of improving pest control through conserving or modifying the environment to enhance survival, reproduction, and behavior of natural enemies 
(Landis et al. 2000). During some phases of their development, they need non-crop resources, such as pollen, nectar, insect honeydews, shelter or alternative preys and hosts (Jervis et al. 1993; Wäckers 2005). Pests feeding causes crop damages/economic losses, and in some phases of their life cycle, pests can use the same non-crop resources consumed by natural enemies (Kevan and Baker 1983; Baggen et al. 1999; Wäckers et al. 2007). Non-crop resources are sometimes enhanced to improve pest control, but the knowledge about the effect of those resources on pests is crucial before increasing their presence in the field in order to hamper pests performance (Baggen and Gurr 1998; Lavandero et al. 2006; Winkler et al. 2009a, b). Many studies analyzed the effect of different food resources (pollen, nectar, insect honeydews, and sugar solutions) on different natural enemies and on pests survival, reproduction, efficiency, or attractiveness (Jervis et al. 1993; Baggen and Gurr 1998; Géneau et al. 2012; AguilarFenollosa and Jacas 2013; Balzan and Wäckers 2013; Beltrà et al. 2013; Gonzalez et al. 2015; Saeed et al. 2015). However, knowledge about the use of non-crop resources by most of the adult pests is still insufficient and as far as we know it has never been studied for the olive moth, Prays oleae (Bernard) (Lepidopteta: Praydidae).

The olive moth diet and development during its larval stage are well known. This is a monophagous herbivorous that feeds on the olive tree. It has three generations per year: i) the phylophagous generation that feeds on leaves and develops during autumn and winter; ii) the anthophagous generation that feeds on flowers and develops during the olive tree blooming; and iii) the carpophagous generation that feeds on fruits and develops during summer. Adult feeding habits are poorly known and they might be a determining factor for the survival and reproduction of the olive moth. Such information is crucial and needs to be investigated. Most adults of Lepidoptera order feed on floral nectar although they may also feed on a variety of other liquids such as honeydews (Kevan and Baker 1983; Jervis et al. 2005; Krenn 2010), with implications on conservation biological control, with risks or benefits of using these non-crop resources for Lepidoptera pests control (Lee and Heimpel 2005; Mevi-Schütz and Erhardt 2005; Begum et al. 2006; Lavandero et al. 2006 Winkler et al. 2009b; Balzan and Wäckers 2013). One hypothesis, which needs to be investigated, is that $P$. oleae feed on pollen and nectar provided by non-crop natural vegetation flowers or on insect honeydews from olive groves and surrounding areas.

Moreover, many studies about pests and natural enemies feeding on non-crop vegetation use a similar set of plants (Araj and Wratten 2015) and these plants are chosen due to their proved positive effect on many natural enemies and sometimes on biological control. For example, Lobularia maritima (L.) Desv., Fagopyrum esculentum M. or Phacelia tanacetifolia Benth were frequently studied (Lee et al. 2004; Lavandero et al. 2006; Balzan and Wäckers 2013; Araj and Wratten 2015). However, these plants are not always native and the potential for biological control of many other species in different agroecosystems are unknown. Some authors have already pointed out the importance of using native plants (Jervis et al. 1993; Fiedler and Landis 2007; Araj and Wratten 2015) that can be better adapted to the local environmental conditions, their use may reduce the risk of nonnative plants invasion, and the economic inputs for farmers. Pollen and nectar provided by these plants might be used as food resources by the olive moth. Additionally, the olive moth might consume honeydews produced by two secondary hemipteran pests which feed on the olive tree, the black scale, Saissetia oleae (Olivier) and the olive psyllid, Euphyllura olivina (Costa) and both co-occur with the anthophagous generation of the olive moth. E. olivina larvae and adults perforate tender tissues of the olive tree and suck the sap of buds (Tzanakakis 2003). E. olivina overwinters as an adult, and oviposition starts in the beginning of spring (coincident with the development of new shoots) and can have various generations per year (Tzanakakis 2003 and references therein).

Here, we studied natural vegetation and honeydews produced by the black scale, $S$. oleae, and the olive psyllid, E. olivina, as potential food resources for adults of $P$. oleae in laboratory assays. The objectives were to investigate the effect of these non-crop resources, occurring in olive groves during the anthophagous generation of olive moth, on the survival and reproduction of the adults of this Lepidoptera pest. Implications of adult feeding on $P$. oleae biology and on biological control conservation are discussed.

\section{Materials and methods}

\section{Experimental design}

Non-crop resources in olive agroecosystems from the northeast of Portugal, Mirandela region, were used to determine their potentiality as food resources for $P$. oleae adults. The food resources selected were $S$. oleae and $E$. olivina honeydews and flowers of the following local plants: Anthemis arvensis L., Andryala integrifolia L. and Crepis capillaris (L.) Wallr. (Asteraceae), Conium maculatum L. (Apiaceae), Jasione montana L. (Campanulaceae), Malva sylvestris L. (Malvaceae) and Trifolium repens L. (Fabaceae). These plant species bloom during spring and are abundant during the anthophagous generation of the olive moth. The flowers were collected in the campus of the Polytechnic Institute of Bragança, northeast of Portugal. Their stems were submerged in water in $15-\mathrm{mL}$ plastic jars 
and closed with parafilm. Honeydews were collected overnight by placing a Parafilm@ strip under infested leaves of olive trees grown in climatic chambers in the laboratory. Given the complex life cycle of the olive moth, there is no rearing methodology of this pest in laboratorial conditions. Therefore, larvae of the anthophagous generation of the olive moth were collected in 15 orchards from the region and in each orchard, 20 larvae were randomly collected in 10 olive trees, in order to avoid clustering in conditions in which the larvae were grown and ensure randomization in the treatment assignment. In laboratory, larvae were transferred into tubes and placed in climatic chambers at $21{ }^{\circ} \mathrm{C}\left( \pm 2{ }^{\circ} \mathrm{C}\right)$ and a 16:8 h L:D (light:dark) photoperiod until adults emergence. Newly emerged couples were transferred into 220 -mL cages. Between 28 and 30 replicates per treatment (22 in C. capillaris treatment) was assembled. All cages were provided with water. Each treatment replicate was provided with flowers of one of the plant species or with honeydews of one of the insects. Approximately, $5 \mathrm{~cm}^{2}$ of flower surface were used by treatment, which correspond to approximately 4 or 5 inflorescences of A. arvensis, A. integrifolia, C. capillaris, J. montana, M. sylvestris, and T. repens and two of C. maculatum (which presents bigger inflorescences), and a Parafilm@ $\odot$ strip of approximately $5 \mathrm{~cm}^{2}$ with honeydew was provided. Foods were replaced three times a week, accordingly to the flowers durability. A negative control (water) and a positive control [water-honey solution $10 \%(\mathrm{~m} / \mathrm{v})$ ] were assembled in jars of $15 \mathrm{~mL}$, with a strip of filter paper as dispenser and closed with Parafilm@ @. Daily mortality and oviposition were recorded. Eggs laid in the cages were counted and marked with a dot to avoid over-counting and eggs laid in the jars were counted and removed.

\section{Data analysis}

\section{Survival}

Survival curves for each treatment were drawn using the Cox estimates of the survival function. Individuals that escaped during the experiment were right censored. Death hazard differences between treatments were checked separately by sexes using Cox's proportional hazard regression model (Cox PHM) through likelihood ratio test and using coxph function of the "survival" package (Therneau 2014) in R (R Core Team 2014). Efron's partial likelihood was used to estimate the parameters of the Cox PHM. The proportional hazard assumption of the Cox regression was confirmed testing the no correlation between the Schoenfeld's residuals and the survival time using the cox.zph function of the same package. Differences between death hazards among sexes for each diet treatment were analyzed following the same procedure performing one different analysis for each diet treatment.

\section{Reproduction}

Firstly, the following parameters were calculated: i) the number of fertile females (percentage of females that laid eggs per treatment in relation to the total number of females); ii) mean pre-oviposition period by fertile couple [ \pm Standard Error (SE)]; iii) the mean oviposition period by fertile couple $( \pm \mathrm{SE})$; iv) the mean lifetime fecundity by fertile couple $( \pm \mathrm{SE})$; v) the total lifetime fecundity per treatment (the sum of all eggs laid by the females within each treatment).

Generalized Linear Mixed Models (GLMM) were used to analyze the influence of treatments on $P$. oleae preoviposition and oviposition periods with treatment as fixed factor and fertile female as random effect. The negative binomial distribution was used for the response variable to account with the over-dispersion. The Log-link was used between the expected value of the response variable and the systematic part of the model. The glmmadmb function from the "glmmADMB" package was used (Skaug et al. 2015). Overall differences were checked using Wald Chi square test with the Anova function from the car package.

Generalized Estimated Equations were used to estimate the autocorrelation between observations $(\alpha=0.536)$ and to account with the repeated sampling in the same subjects using the geeglm function with "AR1" correlation structure from the "geepack" package (Højsgaard et al. 2006). Then, a GLMM was used to fit the fecundity by treatment with treatment as fixed factor and fertile females as random effect and the function corARI from the "nlme" package (Pinheiro et al. 2014) was used to impose the correlation previously calculated. Then, the same procedure used in the previous point was followed.

Following Balzan and Wäckers (2013), a series of generalized linear models (GLM) (with Poisson distribution, or negative binomial distribution to account with overdispersion when needed) were developed to fit the total lifetime fecundity as a function of female longevity for each treatment. The same procedure was followed to analyze the oviposition period as a function of female longevity for each treatment. One outlier was eliminated in the case of $T$. repens treatment.

\section{Results}

\section{Longevity}

Death hazard ratio by diet treatment

The Cox's proportional hazard regression model showed that female and male death hazard were significantly different among diet treatments (females: likelihood 
ratio $=259.3, \quad \mathrm{df}=10, \quad p<0.001 ;$ males: likelihood ratio $=258.1, \mathrm{df}=10, p<0.001)$. Death hazard for females fed on $A$. arvensis, A. integrifolia, $C$. capilllaris and $J$. montana did not differ significantly from the water treatment (negative control). M. sylvestris, C. maculatum, $T$. repens flowers and $E$. olivina honeydews showed significantly lower death hazards than the water treatment but higher than $S$. oleae and honey treatments (positive control) (Fig. 1a). Death hazard for males fed on $C$. capillaris, A. integrifolia and $T$. repens did not differ significantly from the water treatment but was significantly lower than those treatments with A. arvensis and $J$. montana and significantly higher than treatments with $C$. maculatum, M. sylvestris and E. olivina honeydew. Male death hazard with $S$. oleae honeydew did not differ significantly from the honey treatment and both showed a significant lower death hazard than the rest of the treatments (Fig. 1b).

\section{Death hazard ratio among sexes within treatments}

The Cox's proportional hazard regression models did not find significant differences among males and females for the death hazards on water, C. maculatum, T. repens, E. olivina and $S$. oleae honeydew (hazard ratio $>0.883$; df $=1 ; p>0.09$ in all cases). On the other treatments, death hazard was higher for males than for females (Hazard ratio $>1.703$; $\mathrm{df}=1$, $p<0.05$ in all cases).

\section{Reproduction}

Daily oviposition (number of eggs) by fertile females through the experiment is shown in the Appendix (Fig. A1 in Supplementary material). The percentage of fertile females varied between 21 and $95 \%$ among treatments and the mean of eggs laid by females varied between 34.7 $( \pm 8.5)$ and $230.5( \pm 21.8)$. The pre-oviposition period varied between $2.1( \pm 0.5)$ days with honey, and $8.8( \pm 1.6)$ days with $C$. maculatum. The longest oviposition period was accomplished with honey, with $21.3( \pm 2.1)$ days followed by $S$. oleae, with $20.09( \pm 2.54)$ days and the lowest with $A$. arvensis, with $2.4( \pm 0.4)$ days. S. oleae honeydew and honey led to the highest mean number of eggs per fertile female and to the highest total eggs laid per treatment (Table 1).

\section{Pre-oviposition period, oviposition period, and lifetime fecundity}

GLMM outputs fitted for pre-oviposition and oviposition periods and for the lifetime fecundity of $P$. oleae fertile females are shown in the Appendix (Table A1 in Supplementary material). These three variables were significantly affected by the food source (pre-oviposition period: $\chi^{2}=37.7, \mathrm{df}=10, p$ value $<0.001$; oviposition period: $\chi^{2}=10$, df $=195.7, p$ value $<0.001$; lifetime fecundity: $\chi^{2}=89.9, \mathrm{df}=10, p$ value $\left.<0.001\right)$. C. maculatum was the only treatment that caused a significant increase of the

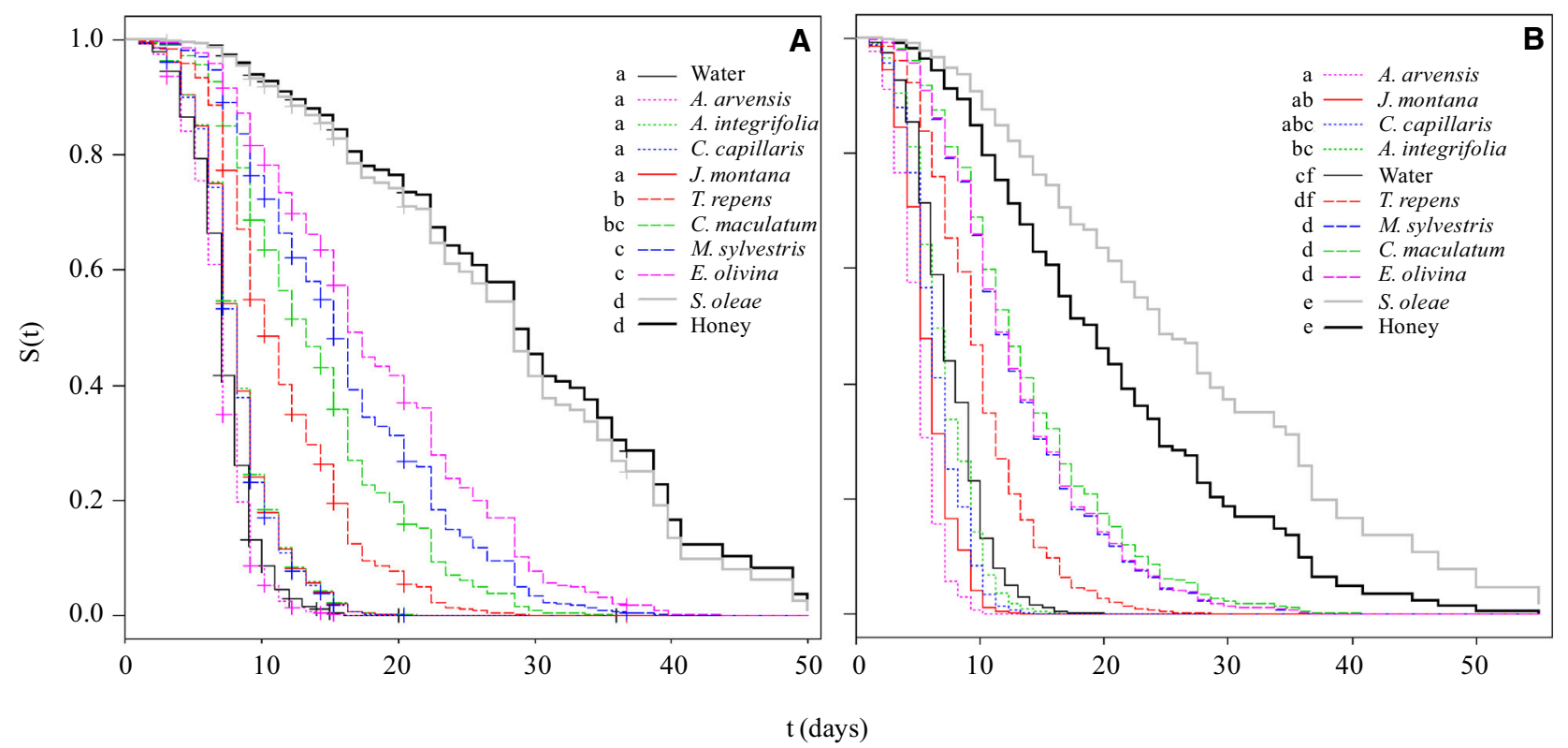

Fig. 1 Cox estimates of the survival function, S(t), for females (a) and males (b). Different letters on the legend indicate significant differences in death hazard among treatments (significance level $<0.05$ ). Crosses indicate censored data 
Table 1 Reproduction parameters of Prays oleae reared on different food sources

\begin{tabular}{|c|c|c|c|c|c|}
\hline Treatments & $\begin{array}{l}\% \text { Fertile } \\
\text { females }^{\mathrm{a}}\end{array}$ & $\begin{array}{l}\text { Pre-oviposition } \\
\text { period }( \pm \mathrm{SE}) \text { (days) }\end{array}$ & $\begin{array}{l}\text { Oviposition period } \\
( \pm \mathrm{SE}) \text { (days) }\end{array}$ & $\begin{array}{l}\text { Mean eggs/fertile } \\
\text { couple }( \pm \text { SE })\end{array}$ & $\begin{array}{l}\text { Lifetime } \\
\text { fecundity }\end{array}$ \\
\hline Water & $90.00(27 / 30)$ & $3.04( \pm 0.30) \mathrm{a}$ & $3.74( \pm 0.32) \mathrm{a}$ & $56.89( \pm 7.78)$ & 1536 a \\
\hline A. arvensis & $66.67(20 / 30)$ & $3.15( \pm 0.51) a b$ & $2.40( \pm 0.37) \mathrm{a}$ & $34.70( \pm 8.48)$ & $694 \mathrm{a}$ \\
\hline A. integrifolia & $80.00(24 / 30)$ & $3.71( \pm 0.62) a b$ & $3.37( \pm 0.42) \mathrm{ab}$ & $41.71( \pm 7.04)$ & $1001 \mathrm{a}$ \\
\hline C. capillaris & $95.45(21 / 22)$ & $4.09( \pm 0.59) \mathrm{ab}$ & $5.33( \pm 0.56) \mathrm{ab}$ & $56.81( \pm 12.48)$ & 1193 a \\
\hline C. maculatum & $21.43(6 / 28)$ & $8.67( \pm 1.55) b$ & $6.83( \pm 1.06) \mathrm{ab}$ & $83.00( \pm 28.40)$ & 498 a \\
\hline J. montana & $60.00(18 / 30)$ & $2.33( \pm 0.37) \mathrm{ab}$ & $3.06( \pm 0.52) \mathrm{ab}$ & $37.78( \pm 11.23)$ & $680 \mathrm{a}$ \\
\hline M. sylvestris & $58.62(17 / 29)$ & $5.06( \pm 1.04) \mathrm{ab}$ & $5.53( \pm 1.19) \mathrm{ab}$ & $70.06( \pm 15.50)$ & $1191 \mathrm{ab}$ \\
\hline T. repens & $41.38(12 / 29)$ & $5.67( \pm 1.04) \mathrm{ab}$ & $6.33( \pm 1.64) \mathrm{ab}$ & $53.67( \pm 11.43)$ & $644 a$ \\
\hline E. olivina & $56.67(17 / 30)$ & $5.94( \pm 1.20) \mathrm{ab}$ & $7.18( \pm 1.37) b$ & $80.88( \pm 19.00)$ & $1375 \mathrm{ab}$ \\
\hline S. oleae & $70.00(21 / 30)$ & $5.81( \pm 1.53) a b$ & $20.09( \pm 2.45) \mathrm{c}$ & $230.57( \pm 21.78)$ & $4842 \mathrm{c}$ \\
\hline Honey & $93.33(28 / 30)$ & $2.01( \pm 0.51) \mathrm{ab}$ & $21.29( \pm 2.08) \mathrm{c}$ & $195.79( \pm 29.76)$ & $5482 \mathrm{bc}$ \\
\hline
\end{tabular}

Different letters indicate significant differences $(p<0.05)$ between treatments after pairwise comparison

${ }^{a}$ The number of fertile females is bar left-sided within brackets and the total number of females is right-sided

pre-oviposition period when compared with water that instead did not significantly differ from the other treatments. Oviposition period on S. oleae honeydew and honey treatments was significantly higher than with the other treatments. The oviposition period was significantly higher on E. olivina honeydew than on water and A. arvensis treatments but did not significantly differ from the other treatments. Fecundity on S. oleae honeydew and honey treatments was significantly higher than on all the other treatments (Table 1).

\section{Oviposition period and lifetime fecundity as a function of longevity}

GLMs showed that the oviposition period was significantly prolonged with the longevity in females fed on $M$. sylvestris, E. olivina, S. oleae and honey (Fig. 2, Table 2). The lifetime fecundity significantly decreased with the longevity on the $C$. maculatum treatment (Fig. 3; Table 2).

\section{Discussion}

Insect feeding is determined by several aspects as availability, appearance or detectability, accessibility, and nutritional suitability of foods (Wäckers 2005). In the present work, the tested food resources are available during the flight period of the anthophagous generation of the olive moth. The selected plants bloom during the middle/ end of spring and usually occur within and/or around olive groves. During this period, both S. oleae and E. olivina produce high amount of honeydew, the former because is in its latest stages of development (Pereira 2004) and the latter because is mainly in the juvenile stages.
Most of the food sources tested resulted suboptimal. This fact is not surprising as many adult insects use more than one food source to fulfill their dietary needs. However, honeydew from $S$. oleae was as good as honey solution (positive control) for $P$. oleae. E. olivina showed also good results. The fact that $S$. oleae honeydew alone (also $E$. olivina in some degree) were enough to maximize $P$. oleae potential survival and reproduction points at the importance of controlling this scale and psyllid insects when in co-occurrence with $P$. oleae.

Nectar concentration, viscosity, composition and amount, the floral architecture and the insect mouthpart structure affect the rate of energy obtained by butterflies (May 1985; Krenn 2010; Winkler et al. 2009a). Many Lepidoptera species can present difficulties to feed on crystalline or more viscous sugary liquids (May 1985; Winkler et al. 2009a). In our work, viscosity could be a reason for the differences found among treatments. Particularly, the lower viscosity of $S$. oleae honeydew than the E. olivina one could explain a better $P$. oleae survival and reproduction with the former. The open corolla of $M$. sylvestris and $C$. maculatum flowers facilitate nectar consumption by insects. $T$. repens produces high quality nectar and is highly attractive to pollinators (Jackobsen and Kristjiansson 1994), however Fabaceae flower architecture may not allow $P$. oleae to properly reach the nectaries.

Honeydew differs from nectar because it contains oligosaccharides synthesized by the insects from the dietary sugars (Wäckers 2000, 2001; Pacini and Nicolson 2007). Generally, nectar has been described to be a better food resource for insects than honeydew (Lee et al. 2004; Wäckers et al. 2008; Vollhardt et al. 2010). Nevertheless, in some cases no differences were found in longevity among insects fed on honeydews and insects fed on sucrose 

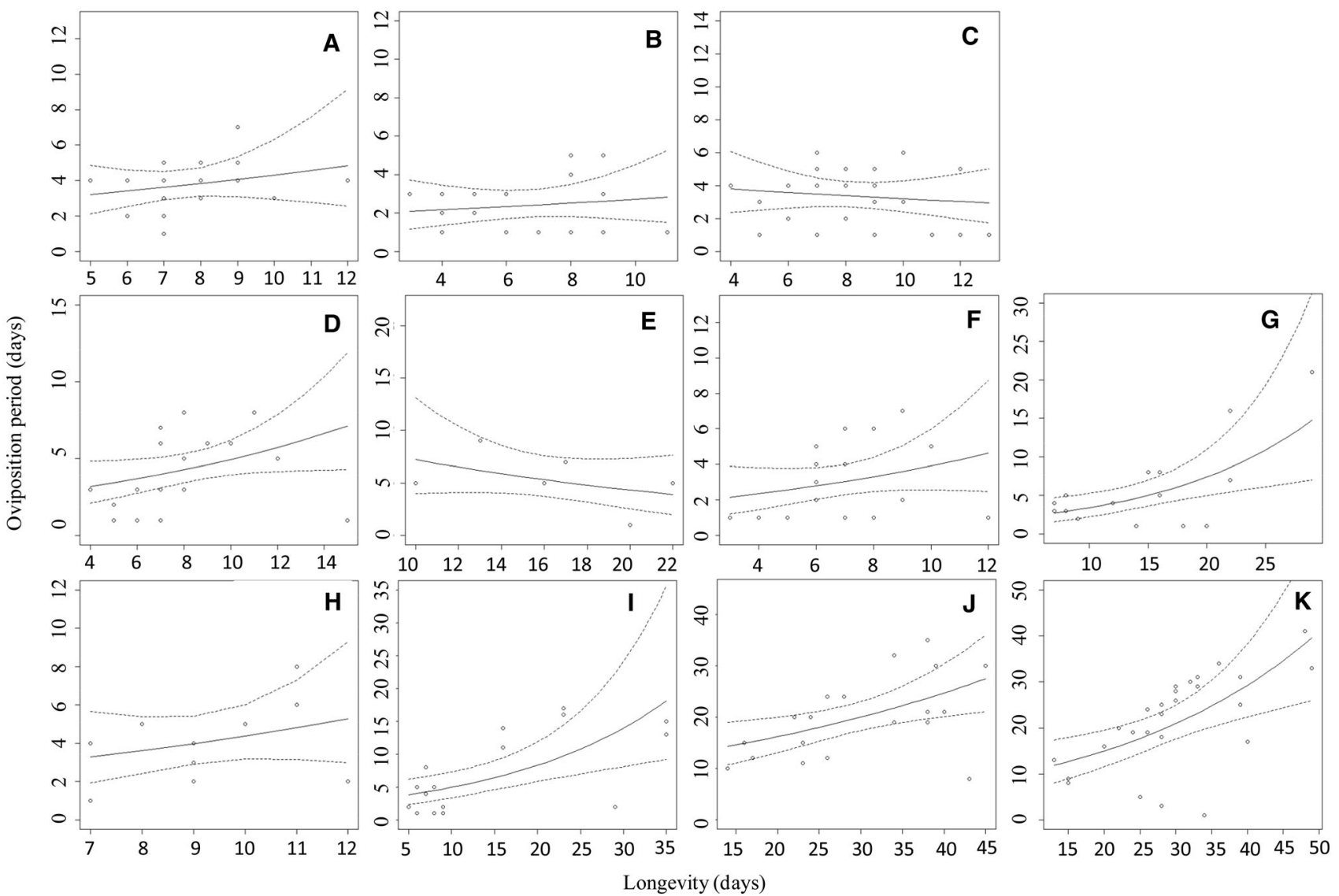

Fig. 2 GLMs plots for oviposition period variation as a function of longevity in each treatment. a Water; b A. arvensis; $\mathbf{c}$ A. integrifolia; $\mathbf{d}$ C. capillaris; e C. maculatum; f J. montana; $\mathbf{g}$ M. sylvestris; $\mathbf{h}$ T. repens; $\mathbf{i}$ E. olivina; $\mathbf{j}$ S. oleae; k Honey

and honey solution (Wäckers et al. 2008) and in others cases honeydew seemed to provide higher nutritional level (Lee et al. 2006). Additionally, honeydews from different species caused different increase in longevity (Wäckers et al. 2008). The sugar composition of hemipteran honeydew depends on both the insect and the plant species (Hendrix et al. 1992). The honeydew composition from $S$. oleae growing on Citrus sinensis L. contained fructose, sucrose and glucose, but no other carbohydrates (Byrne et al. 2003). Wang et al. (2011) found a positive effect of a single meal of $S$. oleae honeydew on the longevities of Bactrocera oleae (Rossi) (Diptera: Tephritidae) and the parasitoids Psyttalia humilis (Silvestri) (Hymenoptera: Braconidae) and Scutellista caerulea (Fonsc.) (Hymenoptera: Pteromalidae). Furthermore, the longevity was not different when fed on black scale honeydew than when fed on clover honey. The predator Chrysoperla carnea (Steph.) (Neuroptera: Chrysopidae) also feed on S. oleae honeydew during its adult phase (Sheldon and MacLeod 1971). To our knowledge, no studies have been performed to analyze the effect of E. olivina honeydew on insects. In this work, honeydews were generally better food resources for $P$. oleae than flowers. S. oleae honeydew was the best food resource for the olive moth, improving male and female survival, the oviposition period and the daily fecundity with respect to the other treatments and being the only treatment that was not different from the positive control. Moths fed on E. olivina honeydew presented also high values in these parameters, being better than the flowers in most cases. Accordingly to Wäckers (2001), evolution would favor sugars that reduce suitability of honeydews when natural enemies of the insect producing honeydew vary in their responses to different honeydew sugars. In olive groves, the populations of $S$. oleae and $E$. olivina probably are not affected by the consumption of their honeydews by $P$. oleae. Moreover, the olive tree canopy is a habitat shared by $P$. oleae adults and larvae, $S$. oleae and E. olivina. This may increase the profitability and consumption of honeydews by saving energy spent in foraging other resources.

Bogg (1997) indicated four lepidopteran categories according to the importance of the adult diet quality to the proportion of mature eggs at adult emergence. Adults from the A category do not feed, emerge with the eggs already 
Table 2 GLMs outputs for estimated regression parameters and standard errors of oviposition period variation and lifetime fecundity as a function of longevity in each treatment

\begin{tabular}{|c|c|c|c|c|c|c|c|c|c|}
\hline & \multirow[t]{2}{*}{ Fixed effect } & \multicolumn{4}{|c|}{ Oviposition period } & \multicolumn{4}{|c|}{ Lifetime fecundity } \\
\hline & & Estimate & $\mathrm{SE}$ & $z$-value & $p$-value & Estimate & SE & $z$-value & $p$-value \\
\hline \multirow[t]{2}{*}{ Water } & Intercept & 0.88 & 0.54 & 1.64 & 0.10 & 4.04 & 0.90 & 4.47 & $<0.001$ \\
\hline & Longevity & 0.06 & 0.07 & 0.84 & 0.40 & -0.0001 & 0.12 & -0.001 & 0.99 \\
\hline \multirow[t]{2}{*}{ A. arvensis } & Intercept & 0.62 & 0.47 & 1.31 & 0.19 & 3.56 & 0.68 & 5.21 & $<0.001$ \\
\hline & Longevity & 0.04 & 0.07 & 0.58 & 0.56 & -0.003 & 0.10 & -0.03 & 0.98 \\
\hline \multirow[t]{2}{*}{ A. integrifolia } & Intercept & 1.45 & 0.42 & 3.47 & $<0.001$ & 4.58 & 0.72 & 6.35 & $<0.001$ \\
\hline & Longevity & -0.03 & 0.05 & -0.57 & 0.57 & -0.10 & 0.08 & -1.24 & 0.21 \\
\hline \multirow[t]{2}{*}{ C. capillaris } & Intercept & 0.87 & 0.34 & 2.52 & 0.01 & 2.63 & 0.80 & 3.27 & $<0.001$ \\
\hline & Longevity & 0.07 & 0.04 & 1.95 & 0.05 & 0.16 & 0.09 & 1.77 & 0.076 \\
\hline \multirow[t]{2}{*}{ C. maculatum } & Intercept & 2.49 & 0.70 & 3.55 & $<0.001$ & 7.94 & 0.90 & 8.82 & $<0.001$ \\
\hline & Longevity & -0.05 & 0.04 & -1.17 & 0.24 & -0.24 & 0.05 & -4.36 & $<0.001$ \\
\hline \multirow[t]{2}{*}{ J. montana } & Intercept & 0.52 & 0.46 & 1.12 & 0.26 & 4.84 & 0.92 & 5.25 & $<0.001$ \\
\hline & Longevity & 0.08 & 0.06 & 1.40 & 0.16 & -0.18 & 0.13 & -1.39 & 0.16 \\
\hline \multirow[t]{2}{*}{ M. sylvestris } & Intercept & 0.46 & 0.43 & 1.06 & 0.29 & 3.70 & 0.72 & 5.17 & $<0.001$ \\
\hline & Longevity & 0.08 & 0.02 & 3.04 & $<0.001$ & 0.04 & 0.05 & 0.78 & 0.43 \\
\hline \multirow[t]{2}{*}{ T. repens } & Intercept & 0.53 & 0.89 & 0.60 & 0.55 & 3.88 & 1.50 & 2.59 & 0.01 \\
\hline & Longevity & 0.09 & 0.09 & 1.01 & 0.31 & 0.02 & 0.16 & 0.13 & 0.90 \\
\hline \multirow[t]{2}{*}{ E. olivina } & Intercept & 1.08 & 0.30 & 3.56 & $<0.001$ & 4.44 & 0.44 & 10.11 & $<0.001$ \\
\hline & Longevity & 0.05 & 0.02 & 3.32 & $<0.001$ & -0.003 & 0.02 & -0.13 & 0.89 \\
\hline \multirow[t]{2}{*}{ S. oleae } & Intercept & 2.36 & 0.25 & 9.60 & $<0.001$ & 5.15 & 0.37 & 13.97 & $<0.001$ \\
\hline & Longevity & 0.02 & 0.01 & 2.72 & $<0.001$ & 0.01 & 0.01 & 0.81 & 0.42 \\
\hline \multirow[t]{2}{*}{ Honey } & Intercept & 2.04 & 0.31 & 6.52 & $<0.001$ & 4.79 & 0.69 & 6.96 & $<0.001$ \\
\hline & Longevity & 0.03 & 0.01 & 3.33 & $<0.001$ & 0.02 & 0.02 & 0.73 & 0.46 \\
\hline
\end{tabular}

In the models fitted for oviposition period Poisson distribution was used for water, A. arvensis, A. integrifolia, C. capillaris, C. maculatum, J. montana and T. repens treatments, and negative binomial distribution for M. sylvestris, E. olivina, S. oleae and honey treatments. In the models fitted for lifetime fecundity negative binomial distribution was used for all the treatments mature and have shorter lifespans. The adult nutrition importance increases progressively in the other categories. Adults in the $\mathrm{C}$ and $\mathrm{D}$ emerge without mature eggs and feed on nectar ( $C$ category) or nectar and pollen ( $D$ category). The fecundity keeps constant for longer times. Jervis et al. (2001) assigned the A category to pro-ovigeny, B to weak synovigeny and $\mathrm{C}$ and $\mathrm{D}$ to synovigeny. For example, Berndt and Wratten (2005) analyzed the relation between lifetime fecundity and longevity of Dolichogenidea tasmanica (Cameron) (Hymenoptera: Braconidae) with several food resources and found that the lifetime fecundity increase was due to the positive effect of the food resource in longevity rather than a direct increase in fecundity. This suggested that $D$. tasmanica is at least partially pro-ovigenic. In the present study, the lifetime fecundity increase was never related to the increase in longevity (Fig. 3; Table 2) and the moths did not lay eggs just after emergence. This suggests that $P$. oleae females may be synovigenic, emerging with no mature eggs. In future research, this should be verified by dissecting recently emerged adult moths to search for mature eggs. According to Boggs
(1997), synovigenic Lepidoptera would feed on nectar, and in the case of the olive moth, likely in insect honeydews as well.

In this study, females fed on water (negative control) laid eggs suggesting that they already emerge with nutritional reserves. This would allow them to mature a minimum of eggs without feeding. Moreover, some of the treatments with better survival performances ( $C$. maculatum, T. repens, E. olivina, S. oleae) did not cause differences in the survival among $P$. oleae sexes but in general the treatments that did not significantly increase the survival compared to water treatment (A. integrifolia, A. arvensis, $C$. capillares, J. montana) caused a higher death hazard for males. This means that, in general, treatments with poorer nutritional value, affect more negatively males than females, suggesting a better nutritional status of females after emergence. This effect would be diluted after males feeding. Exceptions were $M$. sylvestris treatment and honey, where males also showed a higher death hazard. The nutritional reserves of newly emerged females likely proceed from larval nutrition (Boggs 1997). 

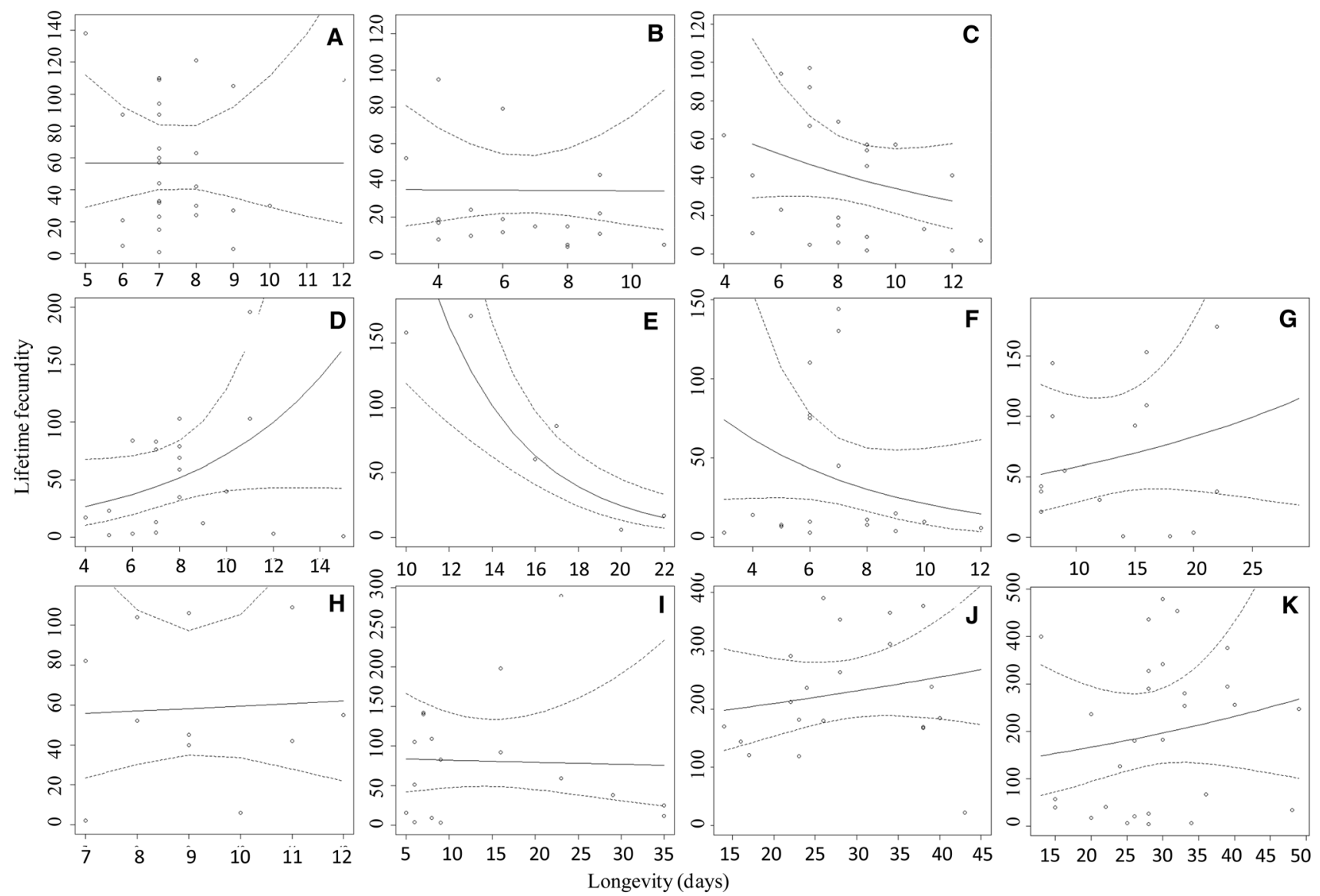

Fig. 3 GLMs plots for lifetime fecundity variation as a function of longevity in each treatment. a Water; b A. arvensis; c A. integrifolia; $\mathbf{d} C$. capillaris; e C. maculatum; f J. montana; $\mathbf{g}$ M. sylvestris; $\mathbf{h}$ T. repens; i E. olivina; $\mathbf{j}$ S. oleae; k Honey

The egg production with $C$. maculatum was less constant and presented the lowest percentage of fertile couples, being that only six females laid eggs. In this case, the lifetime fecundity even decreased with longevity and it was the only treatment that originated a longer oviposition period than the water treatment. C. maculatum is one the most poisonous plants for many organisms due to the alkaloids production (Vetter 2004). Lepidopterans did not pollinate plants containing alkaloids (Kevan and Baker 1983), and in our work C. maculatum seemed to prolong $P$. oleae survival but caused some disruption on reproduction. However, when collecting the plant for the assays, we observed many potential natural enemies, as parasitoids or ladybirds apparently feeding on $C$. maculatum as well as lacewings eggs. This makes it a potential candidate for deeper studies.

Generally, the oviposition period increased with longevity in the treatments that caused longer longevities (honey solution, S. oleae and E. olivina honeydews and $M$. sylvestris), that can be translated to longer $P$. oleae oviposition periods with higher nutritional reserves.

This study was focused in potential food resources for adults of the anthophagous generation of the olive moth, however the adults feeding of phyllophagous and carpophagous generations have never been investigated. Further studies should address this topic.

Once insects may respond differently to food resources in laboratory and in field, laboratory experiments should be complemented with field assays. Lee et al. (2004) found nectar of $F$. esculentum to be a better food resource than honeydew of Aphis glycines Matsumura (Homoptera: Aphididae) for Diadegma insulare Cresson (Hymenoptera: Ichneumonidae) in laboratory experiments. The same group (Lee et al. 2006) found honeydew feeding to provide higher nutrient levels in field experiments. Also laboratory studies establishing nectar exploitation under controlled conditions did not elevate sugar contents of the Plutella xylostella (L.) (Lepidoptera: Plutellidae) and its parasitoid Diadegma semiclausum (Hellen) (Hymenoptera: Ichneumonidae) but in both insects their average overall sugar content increased in flowering margins (Winkler et al. 2009a, b). In our case: i) P. oleae may not fly frequently from the tree canopy to the ground cover, given that, $S$. oleae and E. olivina honeydews seem to be good quality foods for $P$. oleae and are already in that habitat; ii) the food resources that, when studied individually, did not 
have effect in laboratory, when complemented with other resources occurring in the field, could improve $P$. oleae performance. In caged experiments, insects could be deprived of some essential nutrients and mask the real effect of the tested food resources; iii) Intra and interspecific competition and other trophic relationships are not considered in laboratory experiments. For example, the presence of ants foraging on $S$. oleae honeydew can influence the abundance of some $S$. oleae parasitoids (Barzman and Daane 2001) and could also influence $S$. oleae honeydew feeding by $P$. oleae; iv) in caged experiments, the flight energy spent in searching oviposition and foraging sites are not considered (May 1985; Winkler et al. 2006); v) in this study excised flowers were presented to the moths. Excised and intact flowers generally did not affect the parasitoid Aphidius ervi Hal. (Hymenptera: Braconidae) longevity, and excised flowers present some advantages in laboratory experiment related to space, manipulation and number of replicates issues. However, the effect of the flower presentation depends on the insect species and the studied variable. Physiological condition changes with subsequent nectar flow rates, concentration or composition changes could occur (Wade and Wratten 2007).

In conclusion, we found some potential natural foods for $P$. oleae in olive groves from the northeast of Portugal. In general, hemipteran honeydews were better food resources than flowers, pointing at the importance of controlling these insects when co-occurring with the olive moth. Particularly important was $S$. oleae honeydew once it originated as good performance as the positive control. Among the flowers, M. sylvestris caused the best survival and reproduction parameters. C. maculatum increased the longevity but disrupted some reproduction parameters. This species should be deeper investigated in a conservation biological control perspective, since, in the field, it seems to be highly attractive to natural enemies (unpublished observation). At the light of these results, we suggest that $P$. oleae females are synovigenic, emerging with no mature eggs and with reserves for reproduction. Finally, with high nutritional foods, $P$. oleae increased its survival, fecundity and oviposition period. We highly recommend further researches before maintaining, enhancing or introducing these resources in order to confirm their effects on $P$. oleae in the field.

\section{Author contributions}

$\mathrm{MV}, \mathrm{AM}, \mathrm{AB}$, and JAP conceived and designed the research, MV and RM conducted the experiments, MV analyzed the data, MV and JAP wrote the manuscript. All authors read, revised and approved the manuscript.
Acknowledgments The authors are grateful to the Portuguese Foundation of Science and Technology for financial support through the project EXCL/AGR-PRO/0591/2012 "Olive crop protection in sustainable production under global climatic changes: linking ecological infrastructures to ecosystem functions" and Pest-C/EQB/ LA0006/2013. Maria Villa thanks FCT, POPH-QREN, and FSE for $\mathrm{PhD}$ grant (SFRH/BD/70693/2010). This manuscript is part of Maria Villa $\mathrm{PhD}$ Thesis.

\section{References}

Aguilar-Fenollosa E, Jacas JA (2013) Effect of ground cover management on Thysanoptera (thrips) in clementine mandarin orchards. J Pest Sci 86:469-481

Araj SE, Wratten SD (2015) Comparing existing weeds and commonly used insectary plants as floral resources for a parasitoid. Biol Control 81:15-20

Baggen LR, Gurr GM (1998) The influence of food on Copidosoma koehleri (Hymenoptera: Encyrtidae), and the use of flowering plants as a habitat management tool to enhance biological control of potato moth, Phthorimaea operculella (Lepidoptera: Gelechiidae). Biol Control 11:9-17

Baggen LR, Gurr GM, Meats A (1999) Flowers in tritrophic systems: mechanisms allowing selective exploitation by insect natural enemies for conservation biological control. Entomol Exp Appl 91:155-161

Balzan MV, Wäckers FL (2013) Flowers to selectively enhance the fitness of a host-feeding parasitoid: adult feeding by Tuta absoluta and its parasitoid Necremnus artynes. Biol Control 67:21-31

Barzman M, Daane KM (2001) Host-handling behaviours in parasitoids of the black scale: a case for ant-mediated evolution. J Anim Ecol 70:237-247

Begum M, Gurr GM, Wratten SD, Hedberg PR, Helen I, Nicol HI (2006) Using selective food plants to maximize biological control of vineyard pests. J Appl Ecol 43:547-554

Beltrà A, Tena A, Soto A (2013) Reproductive strategies and food sources used by Acerophagus n. sp. near coccois, a new successful parasitoid of the invasive mealybug Phenacoccus peruvianus. J Pest Sci 86:253-259

Berndt LA, Wratten SD (2005) Effects of alyssum flowers on the longevity, fecundity, and sex ratio of the leafroller parasitoid Dolichogenidea tasmanica. Biol Control 32:65-69

Boggs CL (1997) Reproductive allocation from reserves and income in butterfly species with differing adult diets. Ecology 78:181-191

Byrne DN, Hendrix DL, Williams LH (2003) Presence of trehalulose and other oligosaccharides in hemipteran honeydew, particularly Aleyrodidae. Physiol Entomol 28:44-149

Fiedler AK, Landis DA (2007) Attractiveness of Michigan native plants to arthropod natural enemies and herbivores. Environ Entomol 36:751-765

Géneau CE, Wäckers FL, Luka H, Daniel C, Balmer O (2012) Selective flowers to enhance biological control of cabbage pests by parasitoids. Basic Appl Ecol 13:85-93

Gonzalez D, Nave A, Gonçalves F, Nunes FM, Campos M, Torres L (2015) Effects of ten naturally occurring sugars on the reproductive success of the green lacewing, Chrysoperla carnea. BioControl. doi:10.1007/s10526-015-9694-Z

Hendrix DL, Wei Y, Leggett JE (1992) Homopteran honeydew sugar composition is determined by both the insect and plant species. Comp Biochem Physiol B 101:23-27

Højsgaard S, Halekoh U, Yan J (2006) The R package geepack for generalized estimating equations. J Stat Softw 15:1-11 
Jackobsen HB, Kristjiansson K (1994) Influence of temperature and floret age on nectar secretion in Trifolium repens L. Ann Bot Lond 74:327-334

Jervis MA, Kidd NAC, Fitton MG, Huddleston T, Dawah HA (1993) Flower-visiting by hymenopteran parasitoids. J Nat Hist 27:67-105

Jervis MA, Heimpel GE, Ferns PN, Harvey JA, Kidd NAC (2001) Life-history strategies in parasitoid wasps: a comparative analysis of 'ovigeny'. J Anim Ecol 70:442-458

Jervis MA, Boggs CL, Ferns PN (2005) Egg maturation strategy and its associated trade-offs: a synthesis focusing on Lepidoptera. Ecol Entomol 30:359-375

Kevan PG, Baker HG (1983) Insects as flower visitors and pollinators. Annu Rev Entomol 28:407-453

Krenn HW (2010) Feeding mechanisms of adult Lepidoptera: structure, function, and evolution of the mouthparts. Annu Rev Entomol 55:307-327

Landis DA, Wratten SD, Gurr GM (2000) Habitat management to conserve natural enemies of arthropod pests in agriculture. Annu Rev Entomol 45:175-201

Lavandero B, Wratten SD, Didham RK, Gurr G (2006) Increasing floral diversity for selective enhancement of biological control agents: a double-edged sword? Basic Appl Ecol 7:236-243

Lee JC, Heimpel GE (2005) Impact of flowering buckwheat on Lepidopteran cabbage pests and their parasitoids at two spatial scales. Biol Control 34:290-301

Lee JC, Heimpel GE, Gary L, Leibee GL (2004) Comparing floral nectar and aphid honeydew diets on the longevity and nutrient levels of a parasitoid wasp. Entomol Exp Appl 111:189-199

Lee JC, Andow DA, Heimpel GE (2006) Influence of floral resources on sugar feeding and nutrient dynamics of a parasitoid in the field. Ecol Entomol 31:470-480

May PG (1985) Nectar uptake rates and optimal nectar concentrations of two butterfly species. Oecologia 66:381-386

Mevi-Schütz J, Erhardt A (2005) Amino acids in nectar enhance butterfly fecundity: a long-awaited link. Am Nat 165:411-419

Pacini E, Nicolson SW (2007) Introduction. In: Nicolson SW, Nepi M, Pacini E (eds) Nectaries and Nectar. Springer, Dordrecht, pp $1-18$

Pereira JA (2004) Bioecologia da cochonilha negra, Saissetia oleae (Olivier), na oliveira, em Tras-os-Montes. Dissertation, University of Tras-os-Montes e Alto Douro

Pinheiro J, Bates D, DebRoy S, Sarkar D, R Core Team (2014). nlme: Linear and Nonlinear Mixed Effects Models. R package version 3.1-117. http://CRAN.R-project.org/package=nlme

R Core Team (2014) R: a language and environment for statistical computing. R Foundation for Statistical Computing, Vienna. http://www.R-project.org/

Saeed R, Razaq M, Hardy ICW (2015) The importance of alternative host plants as reservoirs of the cotton leaf hopper, Amrasca devastans, and its natural enemies. J Pest Sci 88:517-531
Sheldon JK, MacLeod EG (1971) Studies on the biology of chrysopidae, 2. The feeding behaviour of the adult of Chrysopa carnea (Neuroptera). Psyche 78:107-121

Skaug H, Fournier D, Bolker B, Magnusson A, Nielsen A (2015) Generalized linear mixed models using $\mathrm{AD}$ model builder. $\mathrm{R}$ package version 0.8 .1

Therneau T (2014) A package for survival analysis in S. R package version 2.37-7. http://CRAN.R-project.org/package=survival

Tzanakakis ME (2003) Seasonal development and dormancy of insects and mites feeding on olive: a review. Neth J Zool $52: 87-224$

Vetter J (2004) Poison hemlock (Conium maculatum L.). Food Chem Toxicol 42:1373-1382

Vollhardt IMG, Bianchi FJJA, Wäckers FL, Thies C, Tscharntke T (2010) Nectar vs. honeydew feeding by aphid parasitoids: does it pay to have a discriminating palate? Entomol Exp Appl 137:1-10

Wäckers FL (2000) Do oligosaccharides reduce the suitability of honeydew for predators and parasitoids? A further facet to the function of insect-synthesized honeydew sugars. Oikos 90:197-201

Wäckers FL (2001) A comparison of nectar and honeydew sugars with respect to their utilization by the hymenopteran parasitoid Cotesia glomerata. J Insect Physiol 47:1077-1084

Wäckers FL (2005) Suitability of (extra-) floral nectar, pollen, and honeydew as insect food sources. In: Wäckers FL, van Rijn PCJ, Bruin J (eds) Plant-provided food for carnivorous insects: a protective mutualism and its applications. Cambridge University Press, Cambridge, pp 17-74

Wäckers FL, Romeis J, van Rijn P (2007) Nectar and pollen feeding by insect herbivores and implications for multitrophic interactions. Annu Rev Entomol 52:301-323

Wäckers FL, van Rijn PCJ, Heimpel GE (2008) Honeydew as a food source for natural enemies: making the best of a bad meal? Biol Control 45:176-184

Wade MR, Wratten SD (2007) Excised or intact inflorescences? Methodological effects on parasitoid wasp longevity. Biol Control 40:347-354

Wang XG, Johnson MW, Opp SB, Krugner R, Daane KM (2011) Honeydew and insecticide bait as competing food resources for a fruit fly and common natural enemies in the olive agroecosystem. Entomol Exp Appl 139:128-137

Winkler K, Wäckers FL, Bukovinszkine-Kiss G, van Lenteren J (2006) Sugar resources are vital for Diadegma semiclausum fecundity under field conditions. Basic Appl Ecol 7:133-140

Winkler K, Wäckers FL, Kaufman LV, Larraz V, van Lenteren JC (2009a) Nectar exploitation by herbivores and their parasitoids is a function of flower species and relative humidity. Biol Control 50:299-306

Winkler K, Wäckers FL, Pinto DM (2009b) Nectar-providing plants enhance the energetic state of herbivores as well as their parasitoids under field conditions. Ecol Entomol 34:221-227 